\title{
A Promising Mandibular Molar Trait in Ancient Populations of Ireland
}

\author{
Jaimin D. Weets*
}

State University of New York at Potsdam, NY 13676
The third molar more commonly expressed all forms of MMPT than the first or second molars, with approximately $30 \%$ of all third molars exhibiting a form of MMPT (28\% of lower left third molars and $33 \%$ of lower right third molars). The most commonly expressed form of MMPT was Grade 1, the pit form, most commonly on third molars. Individual Viking specimens from Ireland also exhibited MMPT, and the trait appears to be present in East Asian modern humans at a markedly lower rate of expression, and in Homo pekinensis. Further research will clarify any relationships between MMPT, paramolar tubercles, paramolar structures and the protostylid, as well as the utility of MMPT in dental anthropological biodistancing studies. Dental Anthropology 2009;22(3):65-72.
Dental morphological traits have long been recognized for their importance as phenotypic expressions of genetic differences between human groups. Variations in root and enamel structure were noted in the past by dentists, natural historians, and anatomists (e.g., von Carabelli, 1842; Owen, 1845; Tomes, 1889). Physical anthropologists and dental anthropologists have continued to discover, describe and categorize new forms of dental trait variation (Hrdlička, 1920; Gregory and Hellman, 1926; Weidenreich, 1937; Dahlberg, 1950; Morris, 1975; Scott, 1977; Morris et al., 1978; Harris and Bailit, 1980; Burnett, 1998; Yamada et al., 2000; Correia and Pina, 2002; Edgar and Sciulli, 2004).

Rates of expression for many morphological traits have been recorded in various human population groups. These data have been used to search for patterns of affinity between world regional groups since the beginning of the discipline (e.g., Hrdlička, 1921; Hellman, 1929; Dahlberg, 1945a, Carbonell, 1963; Morris, 1970; Scott, 1980; Scott and Turner, 1997; Hanihara, 2008). But there has been a general imbalance in information for these comparisons. Populations of eastern Asia, the Americas and the Pacific have received much attention over the years (e.g., Wissler, 1931; Kraus, 1959; Suzuki and Sakai, 1964; Kolakowski et al., 1980; Haydenblit, 1996; Swindler and Weisler, 2000; Tocheri, 2002, Matsumura and Hudson, 2005). Fewer studies of European (e.g., Jørgensen, 1955; Axelsson and Kirves- kari, 1977; Toth, 1992; Ullinger, 2002, Coppa et al., 2007) and African (e.g., Hassanali, 1982; Irish, 1997; GuatelliSteinberg et al., 2001; Irish, 2005) groups have been undertaken. While the study of tooth morphology has a rather lengthy history as a sub-field of physical anthropology (Scott and Turner, 1988; Dahlberg, 1991; Scott and Turner, 1997), it is likely that discoveries of novel traits or under-reported variation will be made as new groups, especially in these less-studied regions of the world, are investigated.

It appears that previously unreported variation in an enamel morphological character exists in ancient populations of Ireland. The author noted this variation during a dental anthropological research project that sought to

*Correspondence to: Jaimin D. Weets, Department of Anthropology, 129A MacVicar Hall, 44 Pierrepont Avenue, SUNY Potsdam, Potsdam, NY 13676

E-mail: weetsjd@potsdam.edu

Grant sponsorship: This research was made possible by Grant AY2001/10 from The Heritage Council of Ireland, grants from Research and Graduate Studies Office of The Pennsylvania State University, Research and Sponsored Programs SUNY Potsdam, United University Professions SUNY Potsdam and two Hill Grants from The Pennsylvania State University. 
assess, through the use of the Arizona State University Dental Anthropology System (ASUDAS), the presence of large-scale migrations in ancient time periods of Ireland (Weets, 2004). While recording morphometric variation in specimens from several times periods dating from Ireland's Neolithic (ca. 4,000-1,800 BC) to its Early Christian era (ca. AD 400-1170), an indentation in the enamel crown was first noted on the buccal surface of heavily fragmented and cremated permanent mandibular molars from multi-component megalithic tomb sites.

Initially, this indentation was thought to be a variant of a weak form of the protostylid, which simply had not been described in publications on the ASUDAS (Turner et al., 1991). In addition, the indentation often was not noticed because it was not in the correct location for a protostylid, which was one of the traits scored in the broader research project. Eventually, the discovery of an individual with both a weak grade of protostylid and this indentation on the mandibular molars prompted a closer investigation of this characteristic (Fig. 1).

Observing several specimens, it was found that the indentation was most often in the form of a small pit; a pinpoint circular area of enamel agenesis situated a good distance mesial from the buccal groove. The pit tends to be located high on the buccal surface of the lower molars, suggesting a high likelihood for destruction of the character with even moderate buccally-directed lower tooth wear. This pit differed significantly from the ASUDAS grade 1 buccal pit of the protostylid, located in the buccal groove, as depicted on the ASUDAS protostylid cast and described by Turner et al. (1991). Considering its most common form and the geographic setting, it was noted by the author as the "Irish mandibular molar pit" (IMMP) during data collection and in publication

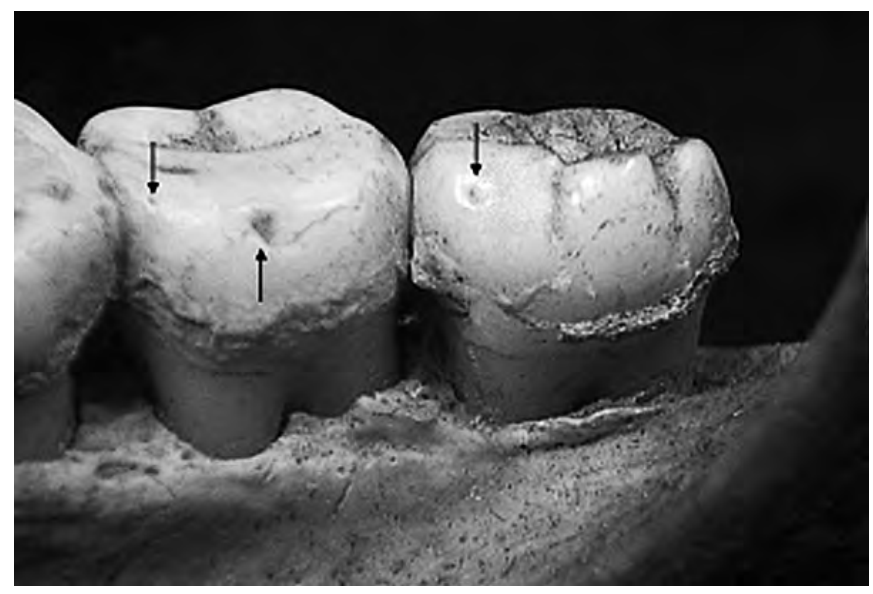

Fig. 1. Grade 1 of MMPT present on second and third left lower molar as shown by downward-pointing arrows (buccal view). Note presence of a weak form of the protostylid on second molar as shown by upwardpointing arrow. Mesial is to the left of the photograph. of his Ph.D. thesis (Weets, 2004). The character, in all its forms, will be referred to as MMPT (mandibular molar pit-tubercle) for the remainder of this article. This label encompasses the range of variation; it avoids ethnic labeling commonly seen in the ASUDAS system; and it allows for any relationship with complex forms of paramolar tubercles that future research may reveal.

\section{The Morphological Variation}

Morphological variation was categorized into three grades that represented the most commonly observed forms of the trait. Assuming that MMPT was either a new trait or had not been reported, other less common forms were assigned to intermediate grades. The intent in the formation of three major grades and of intermediate grades was to provide the fullest description of the trait to inform dental researchers. The accumulation of more data on MMPT variation will likely show some of the intermediate or major grades to be superfluous for biodistancing studies. For those who wish to incorporate the MMPT into a biodistancing study, although this may be premature, the author would suggest application of the same methods as are used with the ASUDAS. Only the three major grades of MMPT would be used, with systematic assignment of intermediate variation to the lower grade of variation (e.g., MMPT Grade 1-2 assigned to MMPT Grade 1) or, in a case of identifying presence of the trait, assignment to the first major grade (i.e., MMPT Grade 0-1 is assigned to MMPT Grade 1). It may be that MMPT proves to have rather clear gradations in morphology that account for its full range of variation, so that a graded plaque for the ASUDAS could be produced. More more research on other populations is necessary to ultimately refine these embryonic categorizations of MMPT variation described below.

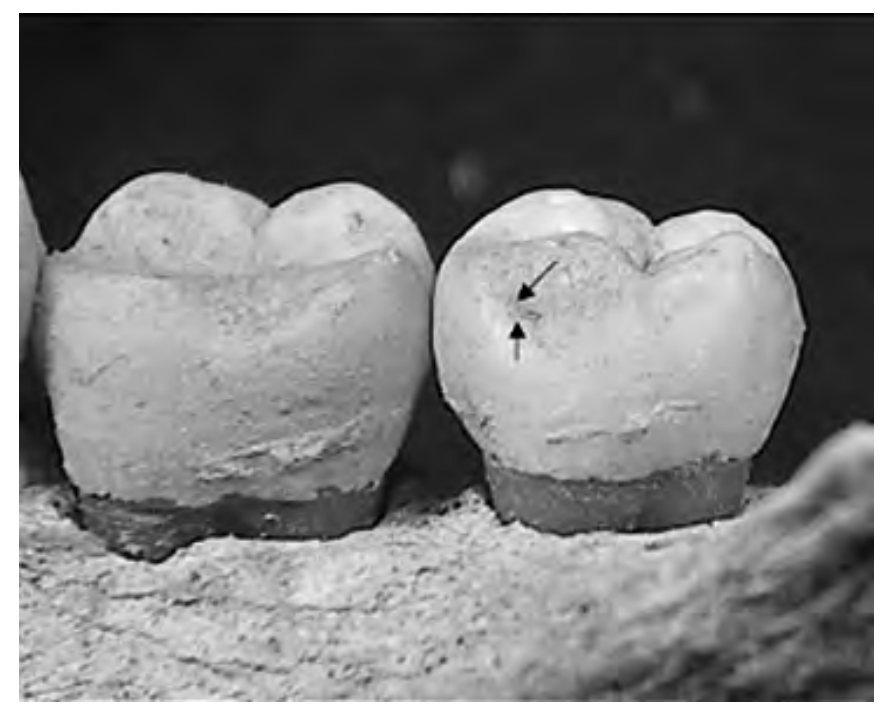

Fig. 2. Grade 2 of MMPT on lower left third molar (buccal view). 
Grade 1 of the feature was assigned to the aforementioned small pit, located mesially and high on the buccal surface of cusp 1 of the lower molars (Fig. 1). The pit was approximately 0.5 to $1 \mathrm{~mm}$ in depth. It was often located approximately 1-2 mm below the intersection of the buccal and occlusal planes, and approximately 1-2 $\mathrm{mm}$ from the intersection of the mesial and buccal faces. While the vast majority of pits encountered during the study were consistent in their location, depth and form, it was not always easy to detect the presence of the character. Several individuals had a slight depression or indentation in the position often occupied by the pit. These were categorized as Grade 0-1 of MMPT to acknowledge what appeared to be a weak expression of the pit form of the trait.

Grade 2 was a groove with its superior terminus approximately in the position often occupied by a Grade 1 pit. From this point, the groove ran in a distalinferior direction at approximately a 30-45 degree angle to the occlusal plane (Fig. 2). In some cases, the superior terminus was a pit with the groove extending in an inferior, distal direction from it. There were a handful of cases where the groove was quite short in its inferior-distal extension, making the "mouth" of the pit elongated. These were classified as Grade 1-2.

Grade 3 has the form of a tubercle without a free apex. Fig. 3 portrays this tubercle, situated mesially on the buccal surface. This photograph shows the strongest expression of a Grade 3 cusp that was encountered during the study. Note that there is no involvement with the tooth's buccal groove (between cusps 1 and 3), even though the MMPT cusp is rather sizeable. In

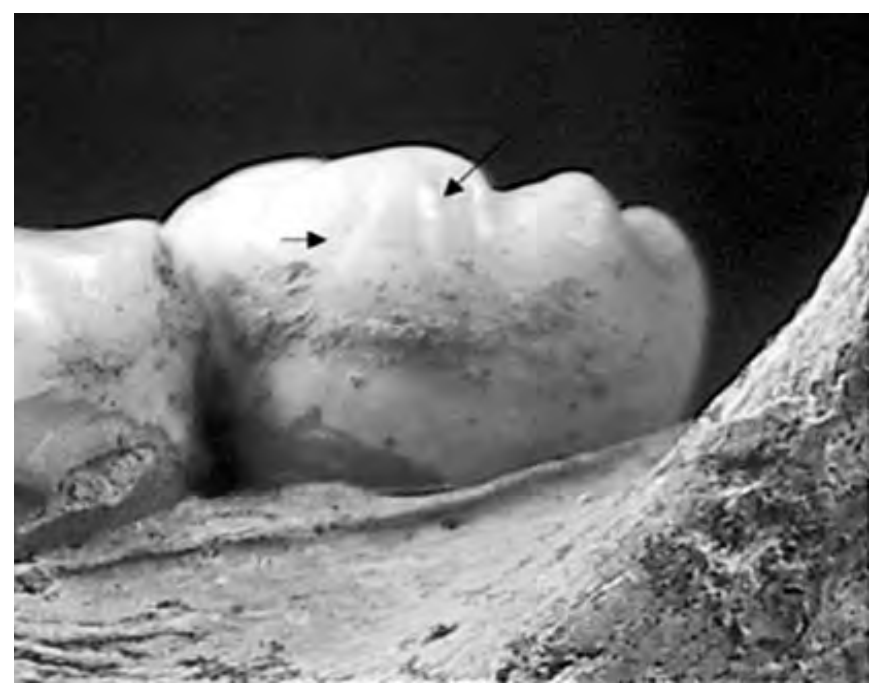

Fig. 3. Grade 3 of MMPT on the lower left third molar of this individual (buccal view). The left arrow points to the mesial groove, and the right arrow points to the distal groove. In combination, these two grooves are marginal limits of this feature. fact, though not quantified, there seemed to a relatively common tendency in these specimens from Ireland for a very weak expression of the buccal groove, or complete lack of the buccal groove, on lower molars.

There were other expressions of the character greater than Grade 2 that appeared to be the beginning of the tubercle present in Grade 3 (Fig. 3). From the position occupied by the pit in Grade 1, a groove ran inferiorly, giving the appearance of a small tubercle separating from the buccal face (Fig. 4). Situated about $1 \mathrm{~mm}$ distal to this groove was a pit. This pit was not in contact with the buccal groove as a protostylid would be, but the pit was lower on the buccal plane of the crown and more distally-situated than the pit from Grade 1. It appears to demarcate the distal side of a weak tubercle, though not as well-formed as in Grade 3 (Fig. 3). Several cases were encountered that were placed in this Grade 2-3 category.

It should be noted that even with categorization of MMPT, distinguishing between MMPT and the protostylid could be difficult. In three cases in the study, distally-directed grooves originating from areas high on the buccal surface of cusp 1 intersected the buccal groove separating cusps 1 and 3 . If one were to have no knowledge of the MMPT character, these grooves intersecting the buccal groove would be most likely assigned to a form of the protostylid. Because of the uncertainty in assignment, these cases were subsequently dropped from consideration in this study as forms of MMPT, and in the greater study as protostylids, though all three cases seemed to be more related in form to the protostylid. Further research on the MMPT trait may provide clues helpful in discerning its more complex forms from those of the protostylid.

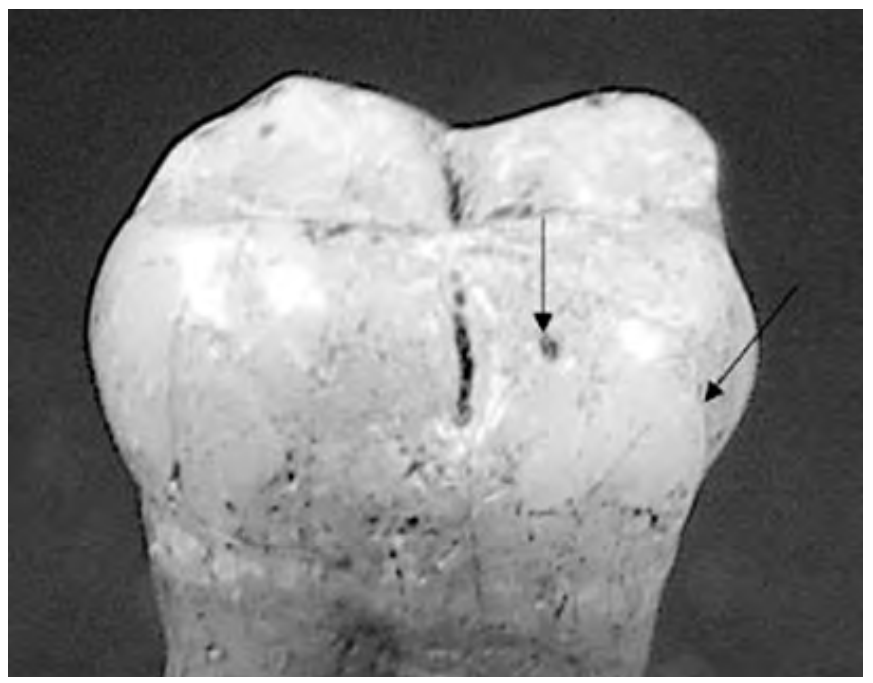

Fig. 4. Lower right second molar exhibiting grade 2-3 of MMPT (buccal view). Note the distally-situated pit mesial to the buccal groove and the sulcus forming at the mesial aspect of the enamel crown. Mesial is to the right of the photograph. 


\section{Geographic and Temporal Distribution}

A review of the literature revealed no report of the range of morphological variation described above for the MMPT. In response to a query, Dr. Christy Turner (pers. comm.) kindly brought to the author's attention an illustration of a similar-looking character on Plate XVI (Fig. 139b of Sinanthropus 36) of Weidenreich's (1937) classic work on Sinanthropus pekinensis. However, no written description of that character could be found in Weidenreich's work. Looking further it seemed that other plates also had drawings depicting what appeared to be the same character. These include Plates XVIII (Fig. 148b of Sinanthropus 99), XIX (Fig. 172b of Sinanthropus 114 ) and XX (Fig. 177b of Sinanthropus 52). Dr. Turner (pers. comm.) also commented that he had observed the character before in his research but had found them at such a low percentage in Asian and Asian-derived populations, where he has done much of his research, that he had not pursued it further. Dr. Joel Irish (pers. comm.), in a discussion of photographs of MMPT with the author, commented that he had recently observed the pit form of MMPT in a Euro-American male student in Alaska, but did not know what the character was when he observed it in that individual, nor had he encountered it before in his research, which includes a number of African groups.

\section{Paramolar tubercles}

Although the range of variation of MMPT does not seem to have been described, publications about other traits appearing on lower molars in the general location of MMPT give cause for caution in suggesting that the trait is unreported. Dahlberg states "the paramolar cusp of Bolk, which is found occasionally on the mesial portion of the buccal surface of lower molars, occurs but rarely on the first molar, more often on the second and third" (1945a, p. 682).

Bolk (1916), in his description of the paramolar tubercle, or paramolar cusp, was not only talking about a cusp forming on the buccal surface of lower molars, but also on the buccal surface of upper molars. As summarized by Dahlberg (1945b), Bolk's contention was that supernumerary teeth, called paramolars, which occasionally appeared buccal to and between the first and second, and second and third molars, were atavisms representing a fuller set of posterior deciduous dentition that had been lost in evolution. These paramolars, when they were not expressed as supernumerary teeth, were thought by Bolk to sometimes join with the permanent molars during development, thus resulting in a cusp found on the anterior-buccal portion of the second and third molars. It was further argued by Bolk (1916) that he had never seen a paramolar tubercle on a first molar in his study of 20,000 cases. In contrast, Dahlberg (1945b) provided several examples of Bolk's paramolar tubercle on lower first molars, as well as an example of paramolar tubercles on all six lower molars. Also, to provide for better terminology, Dahlberg (1945b) suggested that Bolk's paramolar cusp be called a "parastyle" on upper molars and a "protostylid" on the lower molars. These are two traits that are, of course, present in the ASUDAS.

In his 1950 article, Dahlberg returned to the subject and further refined his definition of the protostylid: (1) that it is unrelated to other analogous paramolar structures known generally as "paramolar cusps," (2) that it is associated with the buccal groove, and (3) that it occurs much more commonly on first mandibular molars than do other paramolar structures. With his concentration on the protostylid, Dahlberg left other paramolar cusps an open question. Almost 50 years later, Scott and Turner $(1997$, p. 47, 53) discuss the parastyle of the upper dentition and state that there is little known about some paramolar structures and there is a lack of research on these traits.

Investigating what has been published on paramolar tubercles, Bolk (1916) provides a number of photographs of paramolar cusps in the upper and lower dentition, but the majority is from an occlusal perspective. While there are clear examples of cusps arising on buccal surfaces, it is impossible to see exactly their expression on the buccal surface and how exactly they differ from protostylids because of the occlusal perspective. One photograph (Bolk's Fig. 15) shows the buccal surface, but the tubercles are of much stronger expression than the variation exhibited in Ireland, and some have involvement with the buccal groove. Therefore, there is still quite a question of how exactly these structures are related. Interestingly, there is a third molar in Bolk's Fig. 22 , although he did not mention it, where a pronounced anterior buccal cusp with no buccal groove involvement is portrayed. While some examples of Bolk's paramolar tubercle are likely to be strong expressions of MMPT, there appears to be no previous published information on the range of variation of this mesiobuccal structure as it is exhibited in ancient dentition from Ireland.

\section{METHODS}

Human remains from Ireland's Neolithic (ca. 4,0001,800 B.C.), Bronze Age (2000-900 B.C.), Iron Age (700-100 B.C.) through its Early Christian era (ca. A.D. 400-1170) was the target group of the greater research project. Also included in this research were a few remains from Viking burials in Ireland, dating from contexts after $c a$. A.D. 830. Mallory and $\mathrm{O}^{\prime}$ Donnabhain (1998) provide an inventory of archaeological sites known to have yielded skeletal remains from these Irish time periods and where they are currently curated. Their document served as a guide for selection of sites, and it was the intent of the greater research project to observe all of their listed sites within these time periods. 
In this particular research on MMPT variation, skeletal remains from the holdings of the National Museum of Ireland in Dublin (NMI), the Department of Archaeology at University College, Galway (UCG), the Department of Anatomy at Queen's University, Belfast, Northern Ireland (QUBA), and the Department of Archaeology at Queen's University, Belfast (QUB) were examined. NMI holds the majority of all archaeological human remains from the island, and most of the teeth from this study were examined there.

Across a time span of a few thousand years, there were various mortuary programs, and these distinctive programs sometimes existed at roughly contemporaneous periods. Cremated, secondary burials and inhumed remains were encountered. Deposition of multiple individuals was present in a number of contexts, especially from pre-Christian time periods. There were also a sizeable number of individual inhumations with teeth intact in the mandible, especially from the Bronze Age and the Early Christian period.

In order to systematically study and record MMPT, individuals were separated and dental elements sorted. All lower molars encountered were inspected for the presence of MMPT. Detailed notes describing MMPT were entered in the database on each molar. In addition, the character was assigned one of the three grades using written descriptions, direct comparisons of molars with MMPT variation, and reference to digital photographs. Intermediate examples of variation were assigned grades illustrating the range of variation they encompassed (0-1,1-2, 2-3). Degree of wear was also collected on all molars. In any case where a tooth was too worn, damaged in some manner that the buccal surface could not be examined or were obscured by heavy soil matrix or calculus, the character was assigned a non-score. A 10X hand lens was used to observe trait variation in all lower molars.

The final total of individuals with at least one lower molar was 432 . The database was scanned for information collected on MMPT. In three cases, MMPT could not be discerned from expressions of the protostylid and these were dropped from the study. Wear was often quite heavy; antemortem tooth loss was common; and heavy calculus was encountered rather frequently.
These factors reduced the study sample by more than half, resulting in between 129 and 179 scorable molars depending on tooth type (Table 1 ).

\section{RESULTS}

Table 1 shows frequency rates of MMPT expression in all measureable ancient teeth from Ireland. The strongest expression is in the third molars where approximately 3 out of 10 individuals exhibited the character $(28 \%$ of lower left third molars and $33 \%$ of lower right third molars). The first and second molars show a decidedly low frequency of the trait with ranges between $0 \%$ and $3 \%$ of the sample with the character. The most common expression of MMPT is the pit form, with $10 \%$ of lower left third molars and $19 \%$ of lower right third molars exhibiting this Grade 1 . If one were to include the weak indentation form (Grade 0-1) and the elongated pit/short groove form (Grade 1-2) with Grade 1, then $21 \%$ of lower left third molars and $26 \%$ of lower right third molars have Grade 1 morphology. Percentages for Grade 2 show greater rates of expression of MMPT in the third molar over the first and second molars. In Grade 2-3, second and third molars are essentially equal and in Grade 3, rate of expression is essentially equal for right second and third molars ( $c a$. $1 \%)$ with greater disparity in rate of expression between left second and third molars ( $0 \%$ vs. $2 \%$, respectively).

Three Viking specimens from Ireland not listed in Table 1 were also measured and had a similar percentage of expression - from this decidedly tiny sample - to that of the prehistoric and early historic groups. One specimen (Eyrephort, Co. Galway) had Grade 1 MMPT on its lower left third molar, while its first and second lower left molars had none. A second specimen (Islandbridge, Co. Dublin) had no expression of the trait on its right third molar, the only lower molar representing this individual. The third individual (Kilmainham, Co. Dublin) had two teeth, the left second and third lower molars, which could be scored. The trait present on these two teeth could not be distinguished from a protostylid. This was one of the three cases in the study where a distinction between a protostylid and MMPT could not be made.

TABLE 1. Scorable ancient Irish cases with percentages of character grade expressions by tooth

\begin{tabular}{ccccccccc}
\hline Tooth $^{1}$ & $\mathrm{n}$ & Grade 0 & Grade 0-1 & Grade 1 & Grade 1-2 & Grade 2 & Grade 2-3 & Grade 3 \\
\hline $\mathrm{LM}_{1}$ & 170 & 100.0 & 0.0 & 0.0 & 0.0 & 0.0 & 0.0 & 0.0 \\
$\mathrm{RM}_{1}$ & 151 & 97.9 & 0.0 & 0.7 & 0.7 & 0.7 & 0.0 & 0.0 \\
$\mathrm{LM}_{2}$ & 178 & 97.7 & 0.6 & 1.1 & 0.6 & 0.0 & 0.0 & 0.0 \\
$\mathrm{RM}_{2}$ & 179 & 96.6 & 0.0 & 1.1 & 0.6 & 0.0 & 0.6 & 1.1 \\
$\mathrm{LM}_{3}$ & 131 & 71.6 & 0.8 & 10.2 & 9.8 & 5.3 & 0.0 & 2.3 \\
$\mathrm{RM}_{3}$ & 126 & 67.2 & 1.6 & 19.4 & 4.7 & 5.5 & 0.8 & 0.8 \\
\hline
\end{tabular}

${ }^{1}$ Codes are left (L) and right (R) sides. 


\section{DISCUSSION}

The frequency of expression of MMPT is promising for future application in dental anthropological studies. At least in ancient populations from Ireland, it appears to occur at a rather high frequency, which is somewhat unusual for dental anthropological characteristics in European or European-derived populations. Only traits such as upper second incisor interruption grooves, 4-cusped lower second molars, Carabelli's cusp, 2-rooted upper first premolars and 3-rooted upper second molars as described by Scott and Turner (1997) have rates of expression approximately as high or higher. Many others have rates of expression in only $5-10 \%$ of a given European or European-derived population (Scott and Turner, 1997).

One intriguing question is how MMPT is expressed in other populations. Considering European populations, its appearance in at least one of three Viking individuals, all of whom have been suggested to be from populations external to Ireland based on either grave goods or burial context (NMI museum inventory files for Eyrephort, Kilmainham and Islandbridge; Mallory and O'Donnabhain, 1998; Waddell, 2000), promises a high probability that MMPT will be found in other European samples. It may be possible that one, two or all three of these individuals could be Hiberno/Norse rather than Scandinavian Viking, coming from intermarriage between indigenous Irish and Viking populations, and that the trait might be expressed in a given individual because of indigenous Irish parentage. However, the most clear case of MMPT expression in these supposed Viking individuals is seen in the Eyrephort, Co. Galway specimen, who came from a single burial accompanied by a sword, dagger and shield boss of Viking type (NMI museum inventory file) and has long been recognized by Irish archaeologists as one of the clearest examples of a Viking burial in Ireland (Waddell, 2000). Joel Irish's (pers. comm.) recognition of MMPT in a Euro-American student, though the exact descent of that student is not known, provides further evidence that MMPT may be a relatively common trait in European and Europeanderived peoples.

Another question is the utility of the trait in discerning world regional samples from one another. It may not be possible in European or European-derived populations to use MMPT to distinguish geographic or temporal groups. But, based on a relatively high rate of occurrence in ancient populations of Ireland, a very low rate of occurrence in East Asia (C. G. Turner, pers. comm.) and a trait that had not caught the eye of a researcher in his extensive study of African populations (Irish, pers. comm.) it seems that MMPT would be useful in distinguishing world regional groups from one another. Weidenriech's (1937) depiction of what appears to be MMPT in Homo pekinensis suggests that the trait could be useful in paleoanthropological studies as well.
Finally, there is the lingering question of the novelty of the MMPT. While no publication could be found that depicts mesiobuccal mandibular molar morphology ranging from a pit to a tubercle trait, it is certainly possible that these mesiobuccal pits, grooves and tubercles are weak expressions of what have been referred to as paramolar tubercles on the mandibular dentition (Bolk, 1916), with the exclusion of all forms of the protostylid. Interestingly, although Bolk (1916) reported that he had never noted a paramolar cusp on the first molar, which matches well with the pattern of MMPT, he also states that it was much more commonly found on the second molar than on the third. This pattern apparently applied to both the upper and lower molars (Bolk, 1916). This prevalence of Bolk's paramolar tubercles on the second molar runs contrary to the findings of MMPT expression in this study, where it is the third molar that had equivalent or slightly higher rates of expression than the second molar of Grade 3 of MMPT, which is the closest form of variation to what might be viewed as a paramolar tubercle.

Kustaloglu's (1962) research on upper paramolar tubercles (parastyles) suggests a potentially high degree of symmetry in rates of expression between mandibular and maxillary tubercles. Data on the ancient Irish remains shows parastyle frequency rates of expression of only $1.6 \%, 1.2 \%$ and $1.4 \%$ for the upper first, second and third molars, respectively. Considering the higher grades of MMPT, Grades 2-3 and 3, this pattern of upper and lower symmetry between a known and a potential paramolar structure holds. For the first and second molars on all grades of the MMPT, there are similarly low (or nonexistent) rates of expression that reflect the pattern of expression for the parastyle. However, in the lower grades of MMPT, when the third molar is considered, there is significant dissimilarity. Furthermore, there was never an example of a similar mesiobuccal pit, groove or tubercle structure like the MMPT on the maxillary molars that might reflect the MMPT in the upper dentition of this study population.

Schulze discussed paramolar tubercles and structures: "They appear more frequently on the upper molars ... favoring the second and third. As a rule, they are located on the mesiobuccal cusp but can occur farther distally. Their size varies, and frequently a small depression or enamel groove is found in the corresponding place" (1970, p. 99). This last portion of the passage sounds very much like MMPT, but, reading further, Schulze is discussing paramolar structures on both the upper and lower molars, the reference to enamel grooves apparently comes from a 1926 article by Fabian on upper molars that Schulze cites and in focusing on paramolar tubercles that could appear in the lower dentition "on the first molar and, rarely, on other teeth." Dahlberg's 1950 article is cited where clearly the protostylid would be included among these paramolar tubercles (Schulze, 
1970, p. 100). What had appeared at first glance to be the best description of characters like MMPT awaits further research to distinguish connections and differences between MMPT, Bolk's paramolar tubercle and the protostylid. And, for that matter, further research of the upper molar parastyle may reveal greater variation in paramolar structures of the upper dentition.

\section{CONCLUSIONS}

This report describes the MMPT that is expressed the buccal surface of the mesiobuccal cusp of lower molars. Ths feature occurs in approximately $30 \%$ of specimens from Ireland dating from the Neolithic to the Early Christian period. It appears to have a wide geographic and temporal distribution, as it was present in a small sample of Vikings from Ireland, and, apparently, in specimens from ancient eastern Asia, both modern human and older hominid species. The situation of the MMPT trait on the buccal surface of mandibular molars increases its likelihood of surviving dental attrition. Its higher frequency of occurrence on third molars improves chances for observation relative to buccal traits on worn first and second lower molars. The MMPT also has the potential to be one of the more frequently exhibited dental traits known in European and European-derived populations.

Further study of MMPT will clarify its range of variation and determine what connections, if any, it has to Bolk's mandibular paramolar tubercle, the protostylid, or paramolar structures of the upper dentition. The forms of MMPT illustrated in this article suggest a trait that has promise for future dental anthropological studies.

\section{ACKNOWLEDGEMENTS}

This research was made possible by Grant AY2001/10 from The Heritage Council of Ireland, grants from Research and Graduate Studies Office of The Pennsylvania State University, Research and Sponsored Programs SUNY-Potsdam, UUP SUNY-Potsdam and two Hill Grants. I would like to thank a number of people for their assistance, insights and friendship that made this project a success: George Milner, Jim Wood, Dean Snow, Mark Shriver, and Deryck Holdsworth from Pennsylvania State University; Patrick Wallace, Eamonn Kelly, Mary Cahill, Andy Halpin and Margaret Lannin from the National Museum of Ireland; John Waddell and Angela Gallagher from University College, Galway; Richard Warner and Sinead McCartan from the Ulster Museum, Northern Ireland; Malcolm Fry and Linda Canning from the Department of the Environment, Northern Ireland; Eileen Murphy and David Heylings of Queen's University, Belfast, and a special thanks to Jim Mallory of Queen's University for his insights, enthusiasm and bridges of communication with colleagues, and to he and his family for their hospitality.

\section{LITERATURE CITED}

Axelsson G, Kirveskari P. 1977. The deflecting wrinkle on the teeth of Icelanders and the Mongoloid dental complex. Am J Phys Anthropol 47:321-324.

Bolk L. 1916. Problems of human dentition. Am J Anat 19:91-148.

Burnett SE 1998. Maxillary premolar accessory ridges (MxPAR): worldwide occurrence and utility in population differentiation. MA Thesis, Arizona State University, Tempe.

Carbonell VM. 1963. Variations in the frequency of shovel-shaped incisors in different populations. In: Brothwell DR, editor. Dental anthropology. London: Pergamon Press. p 211-234.

Coppa A, Cucina A, Lucci M, Mancinelli D, Vargiu R. 2007. Origins and spread of agriculture in Italy: a nonmetric dental analysis. Am J Phys Anthropol 133:918-930.

Correia A, Pina C. 2002. Tubercle of Carabelli: a review. Dental Anthropology 15:18-21.

Dahlberg AA. 1945a. The changing dentition of man. J Am Dent Assoc 32:676-690.

Dahlberg AA. 1945b. The paramolar tubercle (Bolk). Am J Phys Anthropol 3:97-105.

Dahlberg AA. 1950. The evolutionary significance of the protostylid. Am J Phys Anthropol 8:15-25.

Dahlberg AA. 1991. Historical perspective of dental anthropology. In: Kelley MA, Larsen CS, editors. Advances in dental anthropology. New York: WileyLiss, Inc., p 7-11.

Edgar HJH, Sciulli PW. 2004. Elongated mandibular premolar: a new morphological variant. Dental Anthropology 17:24-27.

Gregory WK, Hellman M. 1926. Dentition of Dryopithecus and the origin of man. Anthropol Pap Am Mus Nat Hist 28:1-117.

Guatelli-Steinberg D, Irish JD,Lukacs JR 2001. Canary Islands-North African population affinities: measures of divergence based on dental morphology. Homo 52:173-188.

Hanihara T. 2008. Morphological variation of major human populations based on nonmetric dental traits. Am J Phys Anthropol 136:169-182.

Harris EF, Bailit HL. 1980. The metaconule: a morphologic and familial analysis of a molar cusp in humans. Am J Phys Anthropol 53:349-358.

Hassanali J. 1982. Incidence of Carabelli's trait in Kenyan Africans and Asians. Am J Phys Anthropol 59:317319.

Haydenblit R. 1996. Dental variation among four prehistoric Mexican populations. Am J Phys Anthropol 100:225-246.

Hellman M. 1929. Racial characters in human dentition. Proc Am Philos Soc 67:157-174. 
Hrdlička A. 1920. Shovel-shaped teeth. Am J Phys Anthropol 3:429-465.

Hrdlička A. 1921. Further studies on tooth morphology. Am J Phys Anthropol 4:141-176.

Irish JD. 1997. Characteristic high- and low-frequency dental traits in sub-Saharan African populations. Am J Phys Anthropol 102:455-467

Irish JD. pers. comm. A conversation with Dr. Irish about MMPT at the American Association of Physical Anthropologists national meetings in Milwaukee, WI, April 9, 2005.

Irish JD. 2005. Population continuity vs. discontinuity revisited: dental affinities among Late Paleolithic through Christian-era Nubians. Am J Phys Anthropol 128:520-535.

Jørgensen KD. 1955. The Dryopithecus pattern in recent Danes and Dutchmen. J Dent Res 34:195-208.

Kolakowski D, Harris EF, Bailit HL. 1980. Complex segregation analysis of Carabelli's Trait in a Melanesian population. Am J Phys Anthropol 53:301-308.

Kraus BS. 1959. Occurrence of the Carabelli trait in Southwest ethnic groups. Am J Phys Anthropol 17:117-123.

Kustaloglu OA. 1962. Paramolar structure of the upper dentition. J Dent Res 41:75-83.

Mallory JP, O'Donnabhain B. 1998. The origins of the population of Ireland: a survey of putative immigrations in Irish prehistory and history. Emania 17:47-81.

Matsumura H, Hudson MJ. 2005. Dental perspectives on the population history of Southeast Asia. Am J Phys Anthropol 127:182-209.

Morris DH. 1970. On deflecting wrinkles and the Dryopithecus pattern in human mandibular molars. Am J Phys Anthropol 32:97-104.

Morris DH. 1975. Bushman maxillary canine polymorphism. S Afr J Sci 71:333-335.

Morris DH, Glasstone Hughes S, Dahlberg AA. 1978. Uto-Aztecan premolar: the anthropology of a dental trait. In Butler PM, Joysey KA, editors. Development, function and evolution of teeth. London: Academic Press. p 59-67.

NMI site files. National Museum of Ireland archaeological site files housed at the main museum location on Kildare Street, Dublin. Originally consulted by the author in 2001.

Owen R. 1845. Odontography or a treatise on the comparative anatomy of the teeth: their physiological relations, mode of development and microscopic structure in vertebrate animals. London: Hyppolyte Bailliere.

Schulze C. 1970. Developmental abnormalities of the teeth and jaws. In: Gorlin RJ, Goldman HM, editors. Thoma's oral pathology, volume 1, 6th ed. St. Louis: C. V. Mosby Company. p 96-183.

Scott GR. 1977. Classification, sex dimorphism, association, and population variation of the canine distal accessory ridge. Hum Biol 49:453-469.
Scott GR. 1980. Population variation of Carabelli's trait. Hum Biol 52:63-78.

Scott GR, Turner II CG. 1988. Dental anthropology. Annu Rev Anthropol 17:99-126.

Scott GR, Turner II CG. 1997. The anthropology of modern human teeth: dental morphology and its variation in recent human populations. Cambridge: Cambridge University Press.

Suzuki M, Sakai T. 1964. Shovel-shaped incisors among the living Polynesians. Am J Phys Anthropol 22:6572.

Swindler DR, Weisler MI. 2000. Dental size and morphology of precontact Marshall Islanders (Micronesia) compared with other Pacific islanders. Anthropol Sci 108:261-282.

Tocheri MW. 2002. The effects of sexual dimorphism, asymmetry, and inter-trait association on the distribution of thirteen deciduous dental nonmetric traits in a sample of Pima Amerindians. Dental Anthropology 15:1-8.

Tomes CS. 1889. A manual of dental anatomy: human and comparative. London: J. \& A. Churchill.

Toth T. 1992. On the frequency of shovel-shaped incisors in Hungarians. In: Smith P, Tchernov E, editors. Structure, function and evolution of teeth. London: Freund Publishing House Ltd. p 491-499.

Turner CG II, Nichol CR, Scott GR. 1991. Scoring procedures for key morphological traits of the permanent dentition: the Arizona State University Dental Anthropology System. In: Kelley MA, Larsen CS, editors. Advances in dental anthropology. New York: Wiley-Liss, Inc., p. 13-31.

Turner CG II. pers. comm. Letter relating Dr. Turner's recognition of MMPT character in digital photos sent to him by the author and of similar characters in Weidenreich's work on Sinanthropus pekinensis. February 25, 2002.

Ullinger J. 2002. Early Christian pilgrimage to a Byzantine monastery in Jerusalem - a dental perspective. Dental Anthropology 16:22-25.

von Carabelli G. 1842. Anatomie des mundes. Wien: Braumuller und Seidel.

Waddell J. 2000. The prehistoric archaeology of Ireland. Bray, Co. Wicklow, Republic of Ireland: Wordwell Ltd.

Weets JD. 2004 A dental anthropological approach to issues of migration and population continuity in ancient Ireland. Ph.D. thesis. The Pennsylvania State University, University Park.

Weidenreich F. 1937. The dentition of Sinanthropus Pekinensis: a comparative odontography of the hominids. Peiping: Palaeolontologica Sinica. New Series D, No. 1. Whole Series No. 101.

Wissler C. 1931. Observations on the face and teeth of the North American Indians. Anthropol Pap Am Mus Nat Hist 33:1-33. 